\title{
Polyvascular atherosclerotic disease and multiple risk factors: focus on arterial hypertension
}

\author{
Alden Begic*1, \\ Amina Bico', \\ Lana Lekic², \\ Admir Tanovic', \\ Demir Bejtovic', \\ Mehmed Kulic', \\ Mirza Dilic' \\ 'University Clinical Center \\ Sarajevo, Sarajevo, Bosnia \\ and Herzegovina \\ ${ }^{2}$ Faculty of Health Studies, \\ Sarajevo, Bosnia and \\ Herzegovina
}

RECEIVED:

September 11, 2015

ACCEPTED:

September 17, 2015

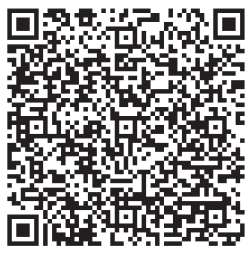

Cardiologia Croatica 2015;10(9-10):238.
KEYWORDS: polyvascular atherosclerotic disease, arterial hypertension, multiple risk factors.

CITATION: Cardiol Croat. 2015;10(9-10):238. | DOI: http://dx.doi.org/10.15836/ccar.2015.238

*ADDRESS FOR CORRESPONDENCE: Alden Begić, Univerzitetski klinički centar Sarajevo, Bolnička 25, 71000 Sarajevo, Bosnia and Herzegovina. / Phone: +387-33-297209 / E-mail: aldenbegic@yahoo.com

ORCID: Alden Begic, http://orcid.org/0000-0002-5374-0892 • Amina Bico, http://orcid.org/0000-0001-6937-1772

Lana Lekic, http://orcid.org/0000-0002-5111-9330 • Demir Bejtovic, http://orcid.org/0000-0002-7678-0344

Mehmed Kulic, http://orcid.org/0000-0003-4864-2013 • Mirza Dilic, http://orcid.org/0000-0002-7309-1455

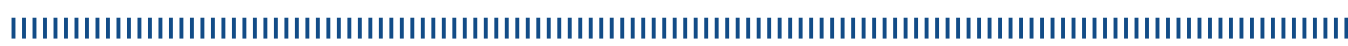

INTRODUCTION: The goal of this study is to evaluate the role of arterial hypertension (HTA) in patients (pts) with atherosclerotic disease (AthD) of coronary arteries (CAD), carotid arteries (CdA) and iliacofemoro-popliteal (IFP) arteries. ${ }^{1-3}$

PATIENTS AND METHODS: The study included a total of 311 pts with with clear clinical AthD. We evaluated the presence of CAD, CdA, and IFP as well as clinical variables: age, gender, arterial hypertension (HTA), tobacco, hyperlipidemia (HLP), obesity (BMI), fibrinogen and diabetes mellitus. The risk factors score was calculated as $\mathrm{x} / 8$. Special focus was given to pts with HTA ( $\mathrm{n}=183)$ who were divided in two subgroups; isolated systolic HTA and systolic/diastolic HTA.

RESULTS: The study included a total of 311 pts, 207 males and 104 females, average age of $64 \pm 11.2$ years. Combination of IFP + CAD was registered in 124 pts, with multiple risk factors (MRF) score 4.35, IFP+CdA was registered in $78 \mathrm{pts}$, with MRF score 4.51, and IFP+CAD+CdA in 109 pts, with MRF score 4.59. HTA was present in $132 \mathrm{pts}(42.4 \%, \mathrm{p}<0.01), 86$ males and 48 females, with the average age $67.8 \pm 12.9$. Isolated systolic HTA was registered in 84 pts (63.6\%), and systolic/diastolic HTA in 48 pts (36.4\%). There was a significant relation between the IFP+CAD pts and isolated systolic HTA, $r=.81, p<0.001$ and borderline significant relation between IFP+CAD+CdA pts and systolic/diastolic HTA, r=42, $p=0.07$.

CoNCLUSIONS: (1) We found a clear link between the PolyAthD and elevated MRF score $(r=.64, p<0.01)$, especially clinical variables HTA $(p<0.01)$ and tobacco $(p<0.01)$. (2) We established a borderline relation rank between dual disease (IFP+CAD and IFP+CdA) and MRF score $(r=.46, p<0.05)$, (3) There was a statistically significant relation between IFP+CAD patients and isolated systolic HTA, $\mathrm{r}=.81, \mathrm{p}<0.001$, and a non-significant relation between IFP+CAD and IFP+CAD+CdA disease and systolic/diastolic HTA, $\mathrm{r}=36, \mathrm{p}=0.9$.

LITERATURE IIIIIIIIIIIIIIIIIIIIIIIIIIIIIIIIIIIIIIIIIIIIIIIIIIIIIIIIIIIIIIIIIIIIIIIIIIIIIIIIIIIIIIIIIIIIIIIIIIIIIIIIII

1. Smith SC Jr, Benjamin EJ, Bonow RO, Braun LT, Creager MA, Franklin BA, et al; World Heart Federation and the Preventive Cardiovascular Nurses Association. AHA/ACCF Secondary Prevention and Risk Reduction Therapy for Patients with Coronary and other Atherosclerotic Vascular Disease: 2011 update: a guideline from the American Heart Association and American College of Cardiology Foundation. Circulation. 2011;124(22):245873. DOI: http://dx.doi.org/10.1161/CIR.0b013e318235eb4d

2. Nakamura T, Kitta Y, Uematsu M, Sugamata W, Hirano M, Fujioka D, et al. Ultrasound assessment of brachial endothelial vasomotor function in addition to carotid plaque echolucency for predicting cardiovascular events in patients with coronary artery disease. Int J Card. 2013; 167(2):555-60. DOI: http://dx.doi.org/10.1016/j.ijcard.2012.01.064

3. Rooke TW, Hirsch AT, Misra S, Sidawy AN, Beckman JA, Findeiss L, et al; American College of Cardiology Foundation Task Force; American Heart Association Task Force. Management of patients with peripheral artery disease (compilation of 2005 and 2011 ACCF/AHA Guideline Recommendations): a report of the American College of Cardiology Foundation/American Heart Association Task Force on Practice Guidelines. J Am Coll Cardiol. 2013;61(14):1555-70. DOI: http://dx.doi.org/10.1016/j.jacc.2013.01.004 